\title{
The Relevance of Learning Processes for IT Implementation
}

\author{
Tanya Bondarouk \\ School of Business, Public Administration and Technology \\ University of Twente, \\ PO Box 217, 7500 AE Enschede, \\ the Netherlands \\ phone: $+31-53-4893666$ \\ fax: $+31-53-4892159$ \\ t.bondarouk@utwente.nl
}

\section{Klaas Sikkel}

School of Electrical Engineering, Mathematics and Computer Science

University of Twente,

PO Box 217, 7500AE Enschede,

the Netherlands

phone: +31-53-4894003

fax: +31-53-4892927

k.sikkel@utwente.nl

Key-words: IT Management, End users, IS Success, Human Resource IS, Organizational Structure, Technology Appropriation, Knowledge Acquisition, Knowledge Sharing, Qualitative Research, Case Study

\begin{abstract}
The starting point of this paper is the belief that it is neither the quality of the technology, nor that of the individual users, but the interactions among people in groups of users concerning a new system that determines the success or failure of IT implementation. Aiming at conceptualization of the role of group learning in IT implementation, we first develop a theoretical framework based on the experiential learning cycle that includes five processes: collective acting, group reflecting, knowledge disseminating, sharing understanding, and mutual adjustment. Second, we illustrate the roles of learning processes in three case studies. Analysis of the interviews with 98 users of information technologies has revealed a unique function of group learning in the IT implementation. It is shown that group learning emerges immediately after a new IT is introduced to the targeted users; it may take different directions (for or against adoption of the technology); it itself can develop during the IT implementation and either progress or take a turn for the worse. The paper elaborates on three organizational conditions important for directing the constructive group learning: managerial support issues, structural and non-structural group characteristics, and technological features that turn group learning in a positive direction.
\end{abstract}

\section{INTRODUCTION}

Almost all modern information technologies (IT) have networked, or collaborative, fragments, and human beings interact with one another while using IT rather than only with the computer, though they might well use computers to do so. These interactions develop within new or existing communities of users, called groups of users in this article. Group 
interactional processes reflect that groups are developing common understandings of the technology they are forced to (or want to) use. In this paper, we theorise the multifaceted complexity of IT implementation by looking at it from the perspective of learning processes, specifically from the perspective of experiential learning. We aim to conceptualise how IT implementation develops through learning processes and to provide empirical support for this conceptualisation.

Some aspects of learning have been already discussed in the IT implementation literature, such as: reflective group processes (Tucker et al., 2001; Hettinga 2002; Schippers, 2003); sharing understanding (Mulder et al., 2002); collaborative knowledge building (Stahl, 2000). In an extended version of the structurational perspective, Orlikowski (2000) proposes looking at "communication, mutual coordination, and storytelling" as important sources for engagement with the system (p.411).

Although some feeling for the topic now exists, and recent research has emphasised the importance of certain elements of learning for IT implementation, systematic insights are still poor.

We start from a definition. Learning in IT implementation is understood as all the interaction processes through which users develop their understandings about a newly introduced system, and that help them in adopting it (Bondarouk and Sikkel, 2005). With this we emphasise that we look at the implementation of IT from its introduction to the targeted employees and till its successful use. Therefore, our main research question is formulated as: What is the role of learning processes in the implementation of IT from its technical installation until its successful use?

To answer this question, in the following sub-sections we elaborate on the conceptualisation of learning in IT implementation from the perspective of experiential learning (Kolb, 1984). After that we discuss the research methodology and present empirical results from three case studies. We finalise with the discussion, conclusions and remarks about future research.

\section{CONCEPTUALIZING LEARNING IN IT IMPLEMENTATION}

Examination of the existing studies has convinced us that there is not much theoretical or empirical research yet completed with a particular focus on the role of learning in explaining and resolving the problems of implementing and using information technologies in organisations.

\section{Learning and IT Implementation: Looking for a Theory}

The studies that address both organisational learning and information technology consider learning as an alternative antidote to the organisational struggles with IT. The overview of the literature about IT and organisational learning by Robey et al (2000) supports this idea, they state: "the link between IT and learning has only begun to be explored" (p. 127).

In the literature about learning in IT implementation, two major streams can be distinguished. First, much has been done in the field of formal training in IT implementation. Such studies deal directly or indirectly with overcoming barriers to acquiring new knowledge in IT use (Robey et al, 2000; Salaway, 1987).

The second, and the main, stream about learning and IT implementation is research on experience-based organisational learning. Strong evidence indicates that an organisation's own experiences provide a knowledge base to guide future actions (Caron et al., 1994; Yetton et al., 1994; Robey \& Newman, 1996; Ang et al., 1997; Robey et al., 2000).

However, although research validates importance of learning through experience, there is a lack of theoretical conceptualisation and therefore generalisations are rare. 


\section{Experiential Learning: a Closer Look}

From the models of experiential learning (e.g., Kegan, Torbert), we have chosen learning theory of Kolb (1984). It is grounded in the concept that people have a natural capacity to learn, and experiences act as a catalyst for engaging in this process (Kayes, 2002).

According to Kolb (1984), learning involves the interplay between two interdependent dimensions of knowledge: acquisition and transformation. Knowledge acquisition demands the resolution of the tension between apprehension (concrete experience) and comprehension (abstract conceptualisation). Another dimension of knowledge is transformation which also shows a dialectical tension: between intention (reflective observation) and extension (active experimentation). The learning cycle includes four steps: doing - reflecting - thinking deciding.

Kolb's (1984) concept combines impulsiveness, feelings, and individual insights with rational thoughts, reflection, and actions. "It maintains the humanistic belief in every individual's capacity to grow and learn, so important for lifelong learning" (Miettinen, 1998, p.170). All of this makes the theory comprehensive, fully generalisable, and attractive to both proponents and opponents.

Opponents of Kolb's model suggested that the emphasis on individual experience should be expanded to include social aspects of learning (Holman et al., 1997; Vince, 1998;

Reynolds, 1999; Kayes, 2002). Overall, limitations of Kolb's model are mainly related to the centrality of individual experience in learning. If we understand learning as changing knowledge and behaviour, then we should acknowledge the importance of social experience for learning.

\section{Towards a Research Framework}

Kolb's cycle describes learning on the individual level. In IT implementation, however, learning is usually a group process in which users communicate, share experiences, and learn from and with each other. For describing learning at the group level, a similar learning cycle can be used. In order to accomodate the exchange of knowledge between group members (not present in individual learning), it has five steps, in stead of four. In earlier research [IRMJ ref] we have proposed and validated the learning cycle on the group level consisting of the following steps: collective actions - group reflecting - knowledge disseminating - sharing understanding - mutual adjusting (Figure 1).

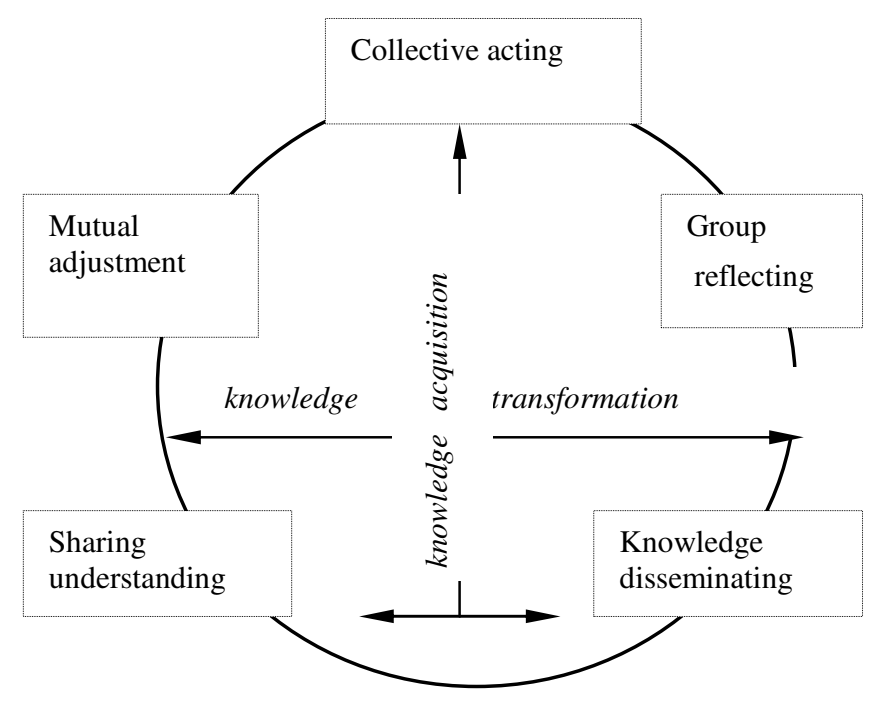

Figure 1. Experience-based learning 
The central challenge lies in the knowledge domain. The group learning cycle is more than multiplying individual learning processes, or 'rephrasing' individual to group activities.

Following from Kolb (1984), the knowledge acquisition dimension involves the tension between 'doing' processes, or actions (apprehension), and 'thinking' (comprehension). Group thinking, in this cycle involves two processes - knowledge disseminating and sharing understanding.

The knowledge transformation dimension of learning is also characterised by a dialectical movement between knowledge intention (group reflecting) and knowledge extension (group deciding, or adjustment, activities).

\section{Collective acting}

A learning cycle begins with the collective experiences and actions when a group of people is given a certain task to perform. This step reflects apprehension of knowledge: when a group is expected to accept new knowledge through perceptions and direct experiences.

We define collective acting in IT implementation as the task-related operations with a system undertaken by members of a group. When a new technology is introduced to targeted employees who are networked together, they will start to operate with the system in order to execute tasks. This can develop through various activities, including operating with basic modules in everyday task performance, or searching for new techniques in the system. The employees can simply replicate the techniques they have learnt during instruction, or they can try to uncover new functionality in using the system. The more experienced members of a group may take an initiative to test new techniques.

\section{Group reflecting}

The next stage is group reflection - the communications upon the extent to which the system supports the performance of tasks (Schippers, 2003). A group is expected to look inwards to reflect upon previously acquired knowledge. Reflection takes place through a variety of activities: discussions, asking questions, declaring difficulties, collective debates, presentations that aim at knowledge externalisation. This is considered crucial in learning from experience because it can help to neutralise biases and errors in group decision-making.

In the situation of the introduction of new IT, group reflecting can take place at various stages: after first operations with the system, or when the implementation is well on its way but it can also happen even before the system is introduced, when future users discuss design issues of the technology. In each case, group reflecting includes communicating about the extent to which the system supports the performance of tasks. Discussions, open dialogue, focus groups, and meetings with a project team might all concentrate on raising difficulties with using the system, comparing it with other software experiences, and with other IT, or raising individual problems in system use. Users might express doubts and suspicions, or trust and beliefs, in the existing ways of solving IT-related difficulties; consider possible reasons for, and outcomes of, mistakes made during operating with the system; or discuss errors in working with various IT functionalities.

\section{Knowledge disseminating}

The knowledge disseminating step introduces the key difference between individual and group learning. It is understood as behaviours of group members that aim at the externalisation of ideas about the IT in order to improve its usage. In transferring individual learning into a cooperative one, the act of knowing becomes more complicated. In a group environment, people would have to 'think together' - that is, they would share the results of 
their individual thoughts. However, knowledge is not something that can be easily passed around (Hendriks, 1999).

Certainly, some information can be codified, stored, and reused to enable effective action at a later stage, but representation is not equivalent to knowledge (Sutton, 2001). There are four modes to the knowledge conversion process that can take place in group learning: externalisation - from tacit knowledge to explicit knowledge; combination - from explicit knowledge to explicit knowledge; internalisation - from explicit knowledge to tacit knowledge; and socialisation - from tacit knowledge to tacit knowledge (Nonaka, 1994; Kwok et al., 2002).

In other words, to break experiences down into meanings, a group would have to go through two phases: firstly, the reconstruction and codifying of knowledge (externalisation and combination); and, only then, could the knowledge can be shared, or transformed, to a tacit form (internalisation and socialisation) (Hendriks, 1999).

Knowledge disseminating during the implementation process of a new IT includes behaviours by the group members that aim to externalise ideas about the system in order to improve its usage. It might emerge in demonstrating the operation of technical modules in both formal (workshops) and informal situations (work breaks), proposing new actions to improve the usage, clarifying difficulties, and peer questioning.

\section{Sharing understanding}

The cycle then moves to sharing understanding, creating a common meaning of the system in terms of the role of the system and its functionality. This involves using insights to help people better see their own situations (Kim, 1993). This internalisation also takes in a great variety of forms: learning by doing, reading books, etc. It is oriented towards those people who look to acquire knowledge. It implies the informal mutual acceptance and respect of diverse ideas and suggestions. Nelson and Cooprider (1996) define sharing understanding as the appreciation of knowledge among group members that affects their mutual performance (p.410).

Knowledge internalisation concerning new technology will lead to a shared meaning of the system among the users. They will share their understanding of the global role of the IT in their company and its intentions for every member of a group, and the design intentions of the developers of the system. An understanding of the technical possibilities and various functionalities (essential and optional) can also be considered as a result of this stage. A group will arrive at a common attitude towards the technical and content functionality of the IT: whether the technology helps to accomplish job tasks and personal responsibilities, and to what extent.

\section{Mutual adjustment}

The final step in cooperative learning is mutual adjustment, activities that aim for collective agreements on the use of the system within a group. In Kolb's model, this step ("deciding") is related to the extension of knowledge when learners move beyond themselves to interact with an external environment. In this stage, a group will engage in activities that lead to a choice to make decisions together, to evaluate, to reject or adopt, or to ignore, tasks, strategies, and new rules.

Some adaptations need to occur: joint regulations, planning, arrangements, and decisions are activities that need to be undertaken by group members in order to move the learning cycle forward. In this phase, goals are presented and ways to achieve them are planned. Adjustment takes place not only before task execution, but also during it (Schippers, 2003).

In a situation involving new technology, this step in the group learning cycle will include activities aimed towards collective agreements to improve the use of the system in the group. Group members may take initiatives to arrange (or request) additional training, instructions, manuals, and other learning activities. Developing regulations in order to improve the use of 
technology can become a crucial issue, especially if the users have never worked before as a group. For example, this could involve decisions about dividing responsibilities for making inputs, and schedules for making outputs. Decisions may be also made about the sorts of documents to be submitted, or about data traffic and classification. The IT might also concern group process issues such as developing regulations for intermediate evaluations of the IT project, supporting on-line chat about topical issues in the project, and news overviews.

The new learning cycle will build upon the existing group experience and knowledge. Planning can also take place during the action or execution of a task, when plans are developed and shaped by seeking feedback, and group reflecting processes. This increases the importance of group reflexivity (Bondarouk, 2006).

We finalise the theoretical discussion by recapitulating the research focus: we are looking at the roles of five learning processes: collective acting, group reflecting, knowledge disseminating, sharing understanding, and mutual adjustment - in the adoption of a newly introduced IT by the users.

\section{RESEARCH METHODS}

We should also look at the larger picture surrounding IT implementation. Learning is not an isolated process, and it may be interrelated with many social and technical issues in an organisation. In order to make our research operational, we will limit it to the, in our view, most important organisational conditions for learning. This will include the characteristics of the information technology, groups of users, and managerial support issues. The operationalisation scheme is shown in Table 1.

\begin{tabular}{|c|c|}
\hline $\begin{array}{l}\text { Constructs } \\
\text { / definitions }\end{array}$ & $\begin{array}{l}\text { Dimensions / } \\
\text { definitions }\end{array}$ \\
\hline \multirow{2}{*}{$\begin{array}{l}\text { Technological prerequisites - the visible, } \\
\text { technical properties of the system that } \\
\text { users are offered. }\end{array}$} & $\begin{array}{l}\text { 1. The role of the system in a company - the intended goal and } \\
\text { managerial reasons for introducing the system. }\end{array}$ \\
\hline & $\begin{array}{l}\text { 2. Specification of the system - domain-based services that the system is } \\
\text { supposed to deliver. }\end{array}$ \\
\hline \multirow[t]{3}{*}{$\begin{array}{l}\text { Group support factors - characteristics } \\
\text { that maintain interactional processes in } \\
\text { the group. }\end{array}$} & $\begin{array}{l}\text { 1. Structural devices - designs that facilitate competent group work } \\
\text { (Hackman, 1987) through the significance and interdependence of job } \\
\text { tasks supported by the system, and how a group is staffed (Campion et } \\
\text { al., 1996). }\end{array}$ \\
\hline & $\begin{array}{l}\text { 2. Non-structural devices of the group - interpersonal understanding and } \\
\text { psychological safety shared by the group (Edmondson, 1999). }\end{array}$ \\
\hline & $\begin{array}{l}\text { 3. Software experience - the level of workmanship in software use in the } \\
\text { group. }\end{array}$ \\
\hline $\begin{array}{l}\text { Managerial support for group learning in } \\
\text { IT implementation. }\end{array}$ & $\begin{array}{l}\text { 1. Organisational arrangements and managerial behavioural patterns for } \\
\text { technology implementation aimed at encouraging use of the system. }\end{array}$ \\
\hline \multirow{5}{*}{$\begin{array}{l}\text { Learning in IT implementation - all the } \\
\text { interactional processes through which } \\
\text { users of IT develop interpretive schemes } \\
\text { about a newly introduced technology that } \\
\text { help them with its implementation. }\end{array}$} & $\begin{array}{l}\text { 1. Collective acting - task-related operations with the system undertaken } \\
\text { by members of a group. }\end{array}$ \\
\hline & $\begin{array}{l}\text { 2. Group reflecting - communicating upon the extent to which the system } \\
\text { supports them in performing tasks. }\end{array}$ \\
\hline & $\begin{array}{l}\text { 3.Knowledge disseminating - behaviors of the group members that aim at } \\
\text { the externalization of ideas about the system in order to improve its } \\
\text { usage. }\end{array}$ \\
\hline & $\begin{array}{l}\text { 4.Sharing understanding - common meaning of the system regarding the } \\
\text { role of the system and its functionality. }\end{array}$ \\
\hline & $\begin{array}{l}\text { 5. Mutual adjustment - activities that aim at collective agreements on use } \\
\text { of the system in the group. }\end{array}$ \\
\hline
\end{tabular}

Table 1. Operationalisation scheme

Three cases studies were conducted in order to explore the role of the learning processes. The goal of the case studies in this research was to exemplify the theoretical discussion on the implementation of IT through learning, and clarifying the contents of the learning processes.

Three companies were selected: a hospital, an insurance company, and a governmental organisation. These are referred to as: Medinet, InsurOrg, and AcademCentre. The case study 
techniques included document analysis, interviews, and participatory observation of IT project activities. We have conducted 87 interviews, each lasting from 45 minutes to 2 hours, and totalling around 121 hours. 98 employees were interviewed (Table 2). Transcripts of all interviews were checked and corrected by the interviewees.

\begin{tabular}{|c|c|c|}
\hline Job position & $\begin{array}{l}\text { Number of } \\
\text { interviews }\end{array}$ & Main responsibilities of interviewees \\
\hline Policymakers & 11 & $\begin{array}{l}\text { Strategic policymaking in organisations, selecting } \\
\text { information systems. }\end{array}$ \\
\hline $\begin{array}{l}\text { Members of the IT project } \\
\text { team }\end{array}$ & 10 & $\begin{array}{l}\text { Steering the IT implementation, providing support } \\
\text { for end-users, performed help-desk duties, } \\
\text { maintaining functional and technical administration } \\
\text { of the system, and sometimes analysing ongoing use } \\
\text { of the system. }\end{array}$ \\
\hline End-users & 67 & $\begin{array}{l}\text { Working with the newly introduced technologies on } \\
\text { a daily basis. }\end{array}$ \\
\hline Technical personnel & 10 & Technical administration of the systems. \\
\hline Total & 98 & \\
\hline
\end{tabular}

Table 2. Type and number of interviews conducted

\section{ORGANISATIONAL CONTEXTS}

\section{Medinet Case Study}

Medinet is a general hospital, founded by the merger of three smaller local hospitals and two polyclinics, one of the largest general hospitals in the Netherlands, with 1,070 beds and around 3,800 employees. Five clusters, distributed over three different locations, comprise 64 departments. In 2001 Beaufort, a module-based workflow system was introduced as a personnel and salary administration system in Medinet. The introduced technology aimed at: increasing the efficiency of personnel administration by restructuring the HRM processes, creating shared information files, leading to the use and exchange of personnel information among users, and incorporating all the various personnel information systems in Medinet. The users of Beaufort were personnel managers in 64 departments. 19 of them participated in the pilot and in this research, of whom $80 \%$ were female. The average age was 36 years; $65 \%$ of them were educated to high school level. Users never worked together before, their main tasks were to advance HRM policy. The administration tasks were considered as secondary, and even as tedious, within the general field of personnel management. The software skills of the users varied, sixteen of the nineteen were familiar with working with IT. Users worked with seven modules for administering documents: Personnel Management, Salary Administration, Sick Leave Administration, Formation and Organisation, Time Registration, Office Link, and Report Generator. In every module users could publish, compose, structure, and store personnel data - but in different manner. Every module required special numerical codification of inputs. Working with Beaufort was obligatory.

The project history included different stages: preparation, negotiation with an external consultancy firm, design, training, piloting, technical adaptation in the period February 1998 - May 2001. In June 2001 Beaufort (one of the modules) was introduced to 19 personnel managers. In July - August 2001 internal evaluations and discussions took place, as well as negotiations with the supplier. A decision was taken to stop the project in September 2001.

\section{InsurOrg Case Study}

InsurOrg is one of the largest insurance companies in the Netherlands, with 12.500 fulltime employees. It unites about 30 formerly independent insurance companies. Main strategy of InsurOrg was to unify all the sub-companies but keep their business images. That forced a knowledge management strategy as one of the approaches to achieve unification of sub- 
companies. In 2001 KennisNet, built on top of Lotus Notes, was introduced as a knowledge management system. It had three main goals: providing technical support for gathering and disseminating professional information; developing common knowledge, as compared to shared information; and supporting community building through the development of common knowledge. The users of KennisNet were 39 product managers in non-life insurance: $38 \%$ female; the average age was 34 years; $74 \%$ of the employees had been educated at the university level. Users were distributed geographically across five locations. The users had two years of collaborating experience. Their main tasks concerned the development and monitoring of the terms, policies, and changes in non-life insurance products. All users were highly skilled in using IT. They could work with the system at four different levels of operation, ranging from passive to active-creative: reading, searching, getting information from the data bank; publishing, or submitting new items; editing, commenting, discussing the existing information; discussing, asking, answering questions; requesting information from colleagues. Working with KennisNet was discretionary. The history of the KennisNet project shows that in April 2001 a first draft of the project plan was ready, followed by the approval by the future users in May 2001. In June - August 2001 the future users intensively discussed the design of the technology. October 2001: KennisNet was introduced to all members of the group. It took one week for the whole group to get familiar with the specifications of the system. After November 2001 the employees did not use the system.

\section{AcademCentre Case Study}

AcademCentre is one of the largest universities in the Netherlands, with more than 23.000 students, more than 7.000 employees (academic personnel 53\%, support and administrative personnel 47\%), and a yearly turnover of $€ 612$ million. There are 14 faculties and 15 support units. In 2002 SAP_HR was introduced in the organisation as a part of the packet

SAP_HR/Employee Transaction Management. It provided the possibility to process personnel information management and handle reports. It had two main goals: replacing an out-dated technology and integration with the already working Financial Model from SAP. The users of SAP_HR were 50 personnel and salary administrators from different units: $65 \%$ female; the average age was $35.7 ; 72.4 \%$ were educated to high school level.

Users never worked as a group before. Their main tasks concerned processing changes in the personnel files of the AcademCentre employees. About 40 tasks were performed through SAP_HR like appointment of an employee (sub-tasks concern appointment of a new employee or an external worker, intern, and various categories of free-lance workers; modification of basic information, payment information, working time registration, and other data, etc. Software skills were not high but sufficient to run SAP_HR. Working with SAP_HR was strictly obligatory. The history of the SAP_HR project developed in several steps: December 2000 -October 2001: preparation, negotiations with an external consultancy firm, design, identification of the requirements ; in November 2001 training of the users took place. On January $1^{\text {st }} 2002$ SAP_HR was introduced in 12 faculties and in all the support and administrative services in the AcademCentre. The period of January - November 2002 saw dramatic difficulties experienced by the users in working with SAP_HR.

\section{FINDINGS FROM THE CASE STUDIES}

We present the findings from the empirical research in three settings. Firstly, the roles of learning processes are identified. Secondly, we discuss the findings about organisational conditions for learning in IT implementation: technological prerequisites and group support factors. And we finalise with the discussion about managerial support necessary to promote learning in IT implementation. 


\section{The Roles of Learning in IT Implementation}

As a result of our research, we propose six statements on the roles of learning in IT implementation:

\section{(1) Learning emerges immediately after a new technology is introduced to the targeted networked users.}

We saw in all the case studies that the users began to talk about the system, spread their interpretations of it, joked, communicated their attitudes towards the system's functionality, or ignored it, complained to each other, and blamed the system - immediately after they had the opportunity to operate it.

\section{(2) Learning may take different directions from the very beginning: for or against adoption of the technology.}

Beaufort brought many changes to the tasks of the decentralised users in the Medinet case study: greater responsibilities for secondary tasks, new content in those tasks, and the necessity to be highly interdependent with other users whom they hardly knew before. They did not want to accept a sudden increase in the importance of tasks that were formerly considered boring. Some users did not even try to work with Beaufort after the stories they heard from those who had. As a result, this group created a consensus of Beaufort as useless from the beginning.

In the InsurOrg case study, KennisNet did not result in changes to the job tasks of the non-life insurance professionals. A lack of clarity about what kind of information to input and share, and with whom and why, lowered the job relevance of KennisNet in the users' perceptions. The following all created disappointment with the system from the beginning: it seemed to work too slowly; the unsophisticated interface required additional efforts to operate KennisNet; overlaps between the insurance subjects that appeared on the screens of KennisNet caused confusion; and there were technical limitations in searching information. As a consequence, the group of KennisNet users developed negative attitudes to the implementation process and the job relevance of the system.

In the AcademCentre case study, personnel and salary administrators experienced significant changes in their daily tasks following the introduction of the SAP_HR system: greater responsibilities for making online inputs, stronger control over these inputs, the necessity to be interdependent, and a need to collaborate across the users of the entire group, many of whom they did not know before. Stress and uncertainty linked to making incorrect inputs to SAP_HR stimulated a negative interpretation of the technology among the users from the start: they did not want to invest a lot of effort and were disappointed with the technology. Further, from the beginning, the users assumed that the system was not useful for their job tasks. These negative feelings about SAP_HR were reinforced daily by accumulation of many disappointments, including small details and misunderstandings with the project team and the communication of these throughout the user group.

These observations support the findings elsewhere that show that one of the main bases for users' interpretations about an information technology is its perceived usefulness for the job tasks (see the findings of Davis et al., 1989; Joshi, 1991; Adams et al., 1992; Morris and Venkatesh, 2000; Venkantesh, 2000; Brown et al., 2002). We have added to these earlier findings by observing that the usefulness of the technology steers the initial direction of the group learning processes, either positively or negatively.

\section{(3) Learning itself can develop during the implementation process and either progress or take a turn for the worse.}

The existing literature does not elaborate on how and why it can develop and, in contrast, our research has shown that group learning is not a fixed matter but can improve or falter as users work with a technology. 
We have observed that learning can continue its development in the direction that it took soon after system introduction. In the InsurOrg case study, learning faltered amongst the KennisNet users once the system was introduced, and it continued in the same direction with the group attitudes going from highly enthusiastic, before the KennisNet introduction, to an indifference towards the system within two months of using it.

We have also seen that learning may change its initial direction. In the AcademCentre case study, learning progressed through many difficulties amongst the SAP_HR users, and changed the group interpretations of the system from extremely negative to optimistic.

\section{(4) Learning has the potential to speed up or slow down the IT implementation process.}

We saw that that learning became an unplanned mechanism for speeding up or slowing implementation, or even for the termination of an IT project (the Medinet case study).

If a group of users appreciate the technological help provided for their tasks, share positive attitudes, help each other, and attribute growth in performance to the system, then, in such a scenario, people will learn the relevant issues about a technology. In so doing, the system is discovered, studied, and better understood; and, with this, the technology becomes more relevant for the job tasks and easier to work with. This will lead to a better and quicker acceptance by the users. In other words, a positive development in group learning will signal quick progress that positively influences interpretations of the technology and leads to constructive action - a quicker acceptance.

The opposite scenario was observed when the users together only complained about the system, perceived it negatively, and convinced each other of its uselessness. Even small details, that in other situations would be ignored, received group attention. In such a scenario, employees learn issues that oppose previous ones. They increase their negative views about the relevance of the system for their tasks and see the technology as too complex to operate. So, the technology becomes less relevant for the job in the opinions of the users, and the learning reinforces the motivation not to accept the system.

We saw that the failure or success of the IT project is magnified in the direction of learning: whether this is oriented towards or against adoption of the technology.

\section{(5) Most progress/regression in learning was observed during the knowledge acquisition processes. Signs of learning progress or regression can be recognised during the first one to two months of the implementation process.}

The analysis has revealed that, in all the case studies, the developments in learning were mainly related to the progress (or lack of) in the knowledge acquisition processes (collective acting, knowledge disseminating, and sharing understanding), and less so by the knowledge transformation processes (group discussions and mutual adjustment). Signs of positive development in the knowledge acquisition dimension in learning were:

- increasing activities involving searching for new possibilities in the system;

- an increasing number of proposals from end-users for improvements to the system and its implementation (we classified those proposals into three types: technical properties of the system, organisation of information to be input, and group regulations concerning use of the system);

- improving conceptual understanding of the technology (especially understanding the why and the what of the technology - and not only the how);

- discovering, recognising, and acknowledging individual user needs in the technology.

(6) The development of the knowledge acquisition processes was promoted by structural arrangements in the groups of users, and in practice this took less effort than the promotion of knowledge transformation processes.

We saw that the knowledge acquisition processes were flexible and dynamic. Therefore, we assert that those responsible for the implementation of a new system should pay special 
attention to the collective acting, knowledge disseminating, and sharing of understanding processes. We also noted that progress was achieved by shaping the structural group characteristics and arrangements such as task reassignment, offering learning possibilities, and setting up discussions. We will elaborate more on this topic in the section on managerial support for IT implementation.

We observed that the group reflecting and mutual adjustment processes were related to the non-structural characteristics of the group such as psychological safety, knowing each other, trust, and experience in working together. These devices take more time and effort to establish in new groups of users, and therefore the knowledge transformation processes will develop more slowly in new groups.

\section{Technological Prerequisites}

In the case studies we observed the implementation of three different technologies: an ERP system (Beaufort), Document Sharing systems (KennisNet), and a WorkFlow system (SAP_HR in AcademCentre). Despite the differences in the architectural design and specifications of the technical parts of these systems, they all have, what we call, collaborative fragments, i.e. modules that require collaboration amongst the users. In all the case studies, the users had to share information and communicate, but with varying intensities and responsibilities, and in different sequences.

We also observed that the greater the level of task interdependence required by the system, the greater the effort that is needed to establish collaboration amongst the users, to redirect group learning towards the level of the entire group of users, and achieve the stable use of the technology.

There was an interesting finding with respect to the freedom given to the employees in their use of the technology. In two cases, the use of the system was mandatory (Beaufort and SAP_HR), while in another it was optional (KennisNet). The case study findings suggest that if system use is voluntary then it must have very clear job relevance to be adopted, i.e. the technology has to demonstrate its own value. In the 'obligatory' cases we saw a need for appropriate conditions to support group learning in the implementation process. These conditions concerned a strong task interdependency through the technology.

\section{Groups Support Factors}

We have divided the group characteristics which are important for 'appropriate' learning in IT implementation into two sets: structural and non-structural. We saw that the structural group characteristics influenced the knowledge acquisition processes in group learning, and the non-structural ones the knowledge transformation processes.

The findings show that there is only one structural characteristic relevant for IT implementation - task interdependence. We observed that the clarity of the task interdependence (division and definitions) affected the process of shaping a group of users during the implementation process. For example, the tasks for the users of KennisNet were not divided and clarified prior to the introduction of KennisNet and, as a consequence, the employees did not collaborate through the system. The implication is that task operationalisation (division, definitions) should be settled and clarified for the users before the introduction of a technology.

There was a lack of empirical support to suggest that other structural characteristics of user groups influence the success of implementation. We observed different types of groups: large versus small (50 users of SAP_HR and 17 users of Beaufort), manager-led versus autonomous (non-life insurance specialists and the decentralised users), and a virtual team (the group of KennisNet users). We did not find any relationship between the type and size of a group and group learning.

The second set of group characteristics is related to such non-structural devices like trust, knowing each other's strengths, and open, risk-taking conversations. These characteristics 
were seen to develop during an IT project. The largest improvement in the non-structural group features we witnessed took place among the users of SAP_HR. At the beginning, they hardly knew each other; but after a couple of months they felt safe enough to speak up. This finding makes it clear that a group can develop during the implementation of a technology.

Those responsible for IT implementation, in our view, have two options in respect of building groups of users in advance. Firstly, they can ignore team building activities on the grounds that it will take too much effort to convince future users of the necessity to become a team before they can sense it for themselves. However, stimulating group discussions and other team building actions must then be undertaken after the system goes live. We saw this scenario in all three situations. The alternative is to begin building non-structural mechanisms such as trust, and knowing and understanding each other during the preparation stages in IT projects, i.e. before the introduction of the system to the users. We did not see this scenario in practice, although we believe that establishing strong non-structural devices within a potential group of the users may lead to a good start in the group reflecting processes when the technology becomes live.

\section{Managerial Support for Group Learning in IT Implementation}

Since the 1970s, information technologies have been viewed as "competitive weapons" in organisations (Parsons, 1983) and, since the same period, social issues have been perceived to be of paramount importance in IT implementation. However, the research by Doherty and King (1998) suggests that there is no relationship between the perceived importance of social issues and their treatment. The authors note that such a pronouncement is worrying as it indicates that many practitioners (especially those responsible for IT implementation) who perceive social issues to be of greater importance than technical ones in IT implementation, are treating those issues only implicitly, or in many cases not at all. No matter how important they think they are, their treatment is often woefully inadequate. Consequently, in many cases, the treatment is simply left to chance (Doherty and King, 1998).

If we look at the reality of IT projects, we must acknowledge that the project teams see various complicating circumstances surrounding IT implementation, including: budget limitations, political games in a company, agreements with a consultancy firm, availability of resources, and technological infrastructure. Having acknowledged the importance of the specific circumstances, our research suggests that project leaders should realise that these complications are explicitly or implicitly transferred to the work reality of the end-users who are forced to, or want to, work with a new technology. Therefore, we would propose that project leaders acknowledge the range of complex issues that groups of users might face. Having accepted this, it should not be a big step to be honest and inform future users about the difficulties foreseen in a project, and at the same time encourage strong teamwork instead of promising a quick fix. There is a need to realise that interaction processes among the users can either speed up or kill the implementation, as we have seen in the case studies. Therefore, it is important to appreciate the role of group learning in IT implementation. This is the first managerial precondition.

In our view, before introducing a system, it is crucial to conceptualise its importance for the users, and to convince them of its relevance. Technology may have, as we saw, a highlevel strategic mission. However, this mission must be modified to the language and needs of the end-users, and therefore transferred to the users' motives. For example, a system's mission to restructure a company will become visible, touchable, and relevant if it is broken down into sub-goals for the users such as making their concrete tasks easier, improving the quality of report generation, and speeding up information searching.

It is also important to fulfil another precondition: the introduction of technology should only start once there is a clear picture about all the job processes that are to be automated. In practice, we saw that managers realised the importance of task operationalisation rather late when users could not overcome their difficulties with the system - and so we would emphasise this precondition. 
When these conditions are met, it is time to think about further project management support. We observed a number of good practices in the three cases that did stimulate constructive group learning. These were:

- Having a help desk or front/back office service on system functionality available for the users at any time,

- Creating and distributing a list of experts on the system's functionality within the group (usually these were the advanced users among the targeted employees whose experience can be very helpful to others),

- Introducing an e-mailing list that includes all the users (or setting up a hot-line chatroom),

- Scheduling informal meetings (such as coffee breaks) for the group of users,

- Agreeing how to involve new employees in the use of the system (what to explain to them, who is responsible, etc.),

- Distributing special notebooks for ideas, proposals, and complaints amongst the users,

- Collecting the proposals that come from the users and reacting to them (negotiating),

- Organising regular evaluation sessions with the users about progress in the project.

This list is not exhaustive, it includes only those practices we saw in real life projects.

Promoting learning possibilities is directly related to group learning as it provides the basis for knowledge and skills exchange. However, the findings show that only 'customised', user-centred, learning opportunities lead to an improvement in group learning. In our view, users do not need the standard large technical manuals that resemble telephone guides. Rather, the users need task-based, job-related manuals on why, when, and how they should use the various services (modules) in the system. The same holds true for the standardised instruction sessions often provided to the users long before they actually work with the system. Training should be designed on the basis of the concrete tasks of the users, with examples from their own work situations, and provided just-in-time when they are required to complete a task.

If we were to advise a management style for those responsible, we would suggest that they remain constantly 'on duty' during the implementation, and keep an eye on the group learning processes to ensure that these develop in the right direction, and that users discuss how to improve the usage of the system rather than how to terminate it. If learning develops impulsively, the adoption of IT may result in complications and high risks for a project as a whole.

\section{CONCLUSIONS}

The starting point of this research is the belief that it is neither the quality of the technology, nor that of the individual users, but the interactions among people in groups of users concerning a new system that determines the success or otherwise of IT implementation. Specific focus of this study is a part of the implementation trajectory that starts after the technology goes live and until its successful use by the targeted employees.

This paper has presented a lens for looking at IT implementation through developments of collective acting, group reflecting, knowledge disseminating, sharing understanding, and mutual adjustment processes. It is not this paper's purpose however, to state that all the problems in IT projects are resolved with the group learning. But it is the purpose to claim that group learning is a (usually unnoticed) mechanism for speeding up or slowing IT implementation, or even for the termination of an IT project.

It is shown that if a group of users appreciates the technological help provided for their tasks, share positive attitudes, and attribute growth in the performance to the technology, then, in such a scenario, people learn relevant issues about a technology. In so doing, the system is discovered, studied, and better understood; and, with this, the technology becomes more relevant for the job tasks and easier to work with. This leads to a better and quicker acceptance of technology by the users. The opposite scenario is when the users together only complain about the system, perceive it negatively, and convince each other of its uselessness. 
They increase their negative views about the relevance of the system for their tasks and see the technology as too complex to operate. So, the technology becomes 'even less relevant' for the job in the opinions of the users, and they learn issues that do not motivate them to accept the system.

Having recognized the importance of the group learning in IT implementation, it is argued that it is vitally important is to stress and accept its role by those who are responsible for IT projects. If managers attempt to advance group learning, then it might become a catalyst for the success of a project. Otherwise the group learning might start an impulsive and unpredicted development that in the end might harm the project.

We have observed conditions that are necessary for group learning to take place such as task interdependence, trust in groups, and certain project management activities. However, to stop at this point misses an important aspect of organisational life. The employees studied (users of technology) went to work and did what they had to do to get their usual jobs done. Their leaders, departments, and the corporate culture, all essential ingredients, were excluded from this research in order to keep the focus on the group and project level. However, further research could greatly contribute to the understanding of the origins and differences in group learning by taking into account different work environments. We suggest that insights could be gained by exploring IT implementation in different types of work and work environments (such as process-, product-, and logistics-based work, and administrative work). Determining whether there is a link between the type of work environment and the type of organisation, and group learning in IT implementation, would add to our research findings.

\section{REFERENCES}

Adams, D.A., Nelson, R.R., \& Todd, P.A. (1992). Perceived usefulness, ease of use and usage of information technology: a replication. MIS Quarterly, 16, (2), 227 - 247.

Ang, K.-T., Thong, J.Y.L., \& Yap, C.-S. (1997). IT implementation through the lens of organizational learning: a case study of INSUROR. In: K. Kumar and J.I. DeGross (Eds.), Proceedings of the $18^{\text {th }}$ International Conference on Information Systems (ICIS'97). December, 15 - 17, Atlanta, Georgia, $331-348$.

Bondarouk, T. (2006). Action-oriented group learning in the implementation of information technologies: results from three case studies. European Journal of Information Systems, 15, (1), 42 $-53$.

Bondarouk, T., \& Sikkel, K. (2005). Explaining Groupware implementation through group learning, Information Resource Management Journal, 18, (1), 364 - 381.

Brown, S.A., A.P. Massey, M.M. Montoya-Weiss \& J.R. Burkman (2002). Do I really have to? User acceptance of mandated technology. European Journal of Information Systems, 11, 283-295. Caron, R.J., Jarvenpaa, S.L., \& Stoddard, D.B. (1994). Business reengineering at CIGNA Corporation: experiences and lessons learnt from the first five years. MIS Quarterly, 18, (3), 233 250.

Davis, F.D., Bagozzi, R.P., \& Warshaw, P.R. (1989). User acceptance of computer technology: a comparison of two theoretical models. Management Science, Aug. 1989, 35, (8), 982 - 1004.

Doherty, N.F., \& King, M. (1998). The importance of organisational issues in systems development. Information Technology \& People, 11, (2), $104-123$.

Hendriks, P. (1999). Why share knowledge? The influence of ICT on the motivation for knowledge sharing. Knowledge and Process Management, 6 (2), 91 - 100.

Hettinga, M. (2002).Understanding evolutionary use of groupware. $\mathrm{PhD}$ thesis, Telematica Instituut Fundamental Research Series, No. 007 (TI/FRS/007), Telematica Instituut, Enschede, The Netherlands.

Holman, D., Pavlica, K., \& Thorpe, R. (1997). Rethinking Kolb's theory of experiential learning: the contribution of social constructivism and activity theory. Management Learning, 28, 135 - 148.

Joschi, K. (1991). A model of users' perspective on change: the case of information systems technology implementation. MIS Quarterly/ June 1991, 229 - 242.

Kayes, D.C. (2002). Experiential learning and its critics: preserving the role of experience in management learning and education. Academy of Management, Learning \& Education, 1, (2), 137 -150 .

Kim, D.H. (1993). The link between individual and organizational learning. Sloan Management Review, 35, (1), 37 - 50. 
Kolb, D. A. (1984). Experiential learning. Experience as the source of learning and development. N.J.: Prentice-Hall, Englewood Cliffs.

Kwok, R.C-W., Lee, J.-N., \& Pi, S.-M. (2002). Role of GSS on collaborative problem-based learning: a study on knowledge externalisation. European Journal of Information Systems, 11, 98 - 107.

Morris, M.G., \& Vekantesh, V. (2000). Age difference in technology adoption decisions: implications for a changing work force. Personnel Psychology, 53, 375 - 403.

Mulder, I., Swaak, J. \& Kessels, J. (2002). Assessing group learning and shared understanding in technology-mediated interaction. Educational Technology and Society, 5 (1), pp. 35-47.

Nelson, K.M. \& Cooprider, J.C. (1996). The contribution of shared knowledge to IS group performance. MIS Quarterly, 20 (4), 409 - 429.

Nonaka, I. (1994). A dynamic theory of organizational knowledge creation. Organization Science, 5 , (1), $41-60$.

Orlikowski, W.J. (2000). Using technology and constituting structures: a practice lens for studying technology in organisations. Organization Science, 11 (4), $404-428$.

Parsons, G.L. (1983). Information technology: a new competitive weapon. Sloan Management Review, Fall 1983, 3 - 13 .

Reynolds, M. (1999). Critical reflection and management education: rehabilitating less hierarchical approaches. Journal of Management Education, 23, 537 - 553.

Robey, D., Boudreau, M.-C., \& Rose, G.M. (2000). Information technology and organisational learning: a review and assessment of research. Accounting Management and Information Technologies, 10, 125 - 155 .

Robey, D., \& Newman, M. (1996). Sequential patterns in information systems development: an application of a social process model. ACM Transactions on Information Systems, 14, (1), 30 - 63.

Salaway, G. (1987). An organisational learning approach to information systems development. MIS Quarterly, 11, (2), $245-264$.

Schippers, M. (2003). Reflexivity in teams. PhD thesis, Amsterdam: Ridderprint offsetdrukkerij b.v.

Stahl, G. (2000). A model of collaborative knowledge building. In: B. Fishman and S. O'ConnorDivelbiss (Eds.), Proceedings of the $4^{\text {th }}$ International Conference of the Learning Sciences (ICLS'2000). June, 14 - 17, Mahwah, NJ: Erlbaum, 70-77.

Sutton, D.C. (2001). What is knowledge and can it be managed? European Journal of Information Systems, 10, $80-88$.

Tucker, A.L., Edmondson, A.C., \& Spear, S. (2001). When problem solving prevents organizational Learning. Harvard Business School working paper 01-073.

Yetton, P.W., Johnston, K.D., \& Craig, J.F. (1994). Computer-aided architects: a case study of IT and strategic change. Sloan Management Review, Summer, 57 - 67.

Venkatesh, V. (2000). Determinants of perceived ease of use: integrating control, intrinsic motivation, and emotion into the technology acceptance model. Information Systems Research, Dec 2000, 11, (4), 342-366.

Vince, R. (1998). Behind and beyond Kolb's learning cycle. Journal of Management Education, 22, $304-319$. 